\title{
Theoretical and Experimental Analysis of FRP Composite Bolted Joint for Rocket Motors
}

\author{
Mr. Kondru Nagendra Babu ${ }^{1}$, Dr. G. Srinivasa Gupta ${ }^{2}$ \\ ${ }^{I}$ (Mechanical Department, VNR Vignana Jyothi Institute of Engineering \& Technology, India) \\ ${ }^{2}$ (Mechanical Department, VNR Vignana Jyothi Institute of Engineering \& Technology, India)
}

\begin{abstract}
This investigation deals with composite plates joined with bolts under tensile loading. A Fiber reinforced composite laminates made of E-glass fiber with phenolic resin as matrix material was fabricated using standard hand layup techniques and joined together using bolts and nuts. The objective of the work is to design bolted joint for rocket motor casing by using Standard method. Testing was done according to ASTM D5961: Procedure ' $B$ ' - the standard test for bearing response of single shear two piece polymer matrix composite laminate. It also includes the manufacturing of composite laminates by studying the properties of $E$ glass and phenolic resin to enhance the properties by adding filler material. Due to unavailability of S-glass and cost factor E-glass is selected to make coupons. The other aim of the project is to analyze the design by computational study. The modeling is done by using CATIA V5 and the stress analysis and couple field analysis is done by using ANSYS 15. The evaluated strength properties from theoretical approaches have been compared with experiments carried out using standard testing methods to validate results.
\end{abstract}

Keywords: bolted joint, CATIA V5, ANSYS 15,E-glass, phenolic resin.

\section{Introduction}

Bolted Joints are one of the most common elements in construction and machine design. They consist of fasteners that capture and join other parts, and are secured with the mating of screw threads. Some of the materials used are ASTM A193 Alloy steel and stainless steel bolting materials for high temperature or high pressure service. ASTM A307 Carbon steel bolts and studs, 60,000 psi tensile strength. ASTM A320 Alloy steel and stainless steel bolting materials for low temperature service.[1] Sayed A. Nassar Vinayshankar L. Virupaksha Saravanan Ganeshmurthy provided an experimental and analytical investigation of the behavior of a double bolted single lap shear composite joint. Various scenarios of bolt tightness are considered for compositeto-composite and composite-to-aluminum bolted joints. Progressive damage analysis is provided for the composite coupons in two regions; namely, the surface under bolt heads and near the contact with the shank of the bolt.[2] Yanyao Jiang, Ming Zhang, Chu-Hwa Lee, explained Both experimental investigation and finite element analysis were conducted to explore the mechanisms for the early stage self-loosening of bolted joints under transverse loading.[3] Balaji R. et al. explained the effect of micro Silica addition to Phenolic resin at 5\%, $10 \%, 15 \%$ and $20 \%$ for finding out the better and effective mechanical properties and concluded that, better mechanical properties are obtained at $15 \%$ of micro Silica. [4] Vesna Rodic has discussed the possibilities of different filler agents to Phenolic resin. The selection of type of filler will be depending upon type of application.

Damage analysis of double bolted single lap shear joint and various scenarios of bolt tightness are studied. ASTM standard method for bearing response of composite bolted joint are studied and analyzed. Testing method is discussed.

\section{Joint Design}

Loads can be applied to bolted joints in a number of different ways, each of which produces unique effects on the joint. These effects result from the way the joint is loaded, as well as how the joint responds to the load. Some of the various load types include tensile, shear and bending. The type of bolted joint derives its name from the external load applied to the joint.

There are two main types of bolted joint designs:

1. Tension joints 2.Shear joints

A. A Tension joint, as illustrated in the figure, is affected by loads that try to pull the joint apart. The forces on the joint and those on the bolts are roughly parallel to the axes of the bolts. All tensile forces try to stretch and/or separate the joint. The tension load, no matter how small, will add to the stress in the bolt and/or partially relieve the joint. 
The bolts in a tension joint must act like clamps. The tightening of the bolt and nut produces a tensile pre-stress, which is approximately equal to the compressive stress introduced in the joint material. The behavior and life of the joint depends on how tightly the bolts clamp and how long they can maintain their preload.

Proper amount of tensioning of the bolts is vital. With too little clamping force, the joint may loosen. If the joint is exposed to cyclical loads, too little clamping force can shorten the bolt's fatigue life. Too much clamping force can also cause severe problems. By over-tightening the bolt, one may exceed the proof load of the bolt. Even if the bolt does not fail during assembly, it may later break under the external tensile load. Over-tightening of the bolt can also encourage the advancement of hydrogen embrittlement or stress corrosion cracking. The joint members can also be damaged or warp from too much clamp force.

The overriding concern with the tension joint is its reliance on bolt tension or preload. If the clamping force is not correct, the joint can fail in several ways; either by bolt fatigue, vibration loosening, stress corrosion cracking or hydrogen embrittlement.

B. A Shear joint is one in which the applied loading is at right angles to the fastener axis; that is, across the bolt shank. Shear joint failure occurs when the joint members are slipped sideways past each other, and eventually cut the fastener

With some shear joints; the ultimate joint strength depends only upon the shear strength of the bolts. This type of joint is referred to as a "bearing type" joint. The amount of tension created in the bolts during assembly is relatively unimportant as long as the fastener is retained in the assembly. The joint member is allowed to slip until the fasteners come into "bearing" and prevents further slip. The fastener in this assembly is basically used as a pin.

Other types of shear joints rely on initial clamp load to resist slip. This type of joint requires a frictional force between the joint members. The shear forces have to overcome the friction developed by the clamp load, which in most cases will be far more than the actual "shear strength" of the fastener itself. This type of joint is common in the structural steel construction industry and may be referred to as a friction-type or slip-critical joint.

Unfortunately, many joints are rarely loaded in pure shear or tension. Some applications subject the joint to a bending force, which results in a combination of tension, and shear load acting simultaneously on the fastener. Extreme caution must be taken when working with a joint subjected to bending.

Usually designers would like to employ the highest clamping force the parts can withstand in order to compensate for some of the anticipated losses in preload. However, there are several limitations to the assembly preload. Too much force on the joint may damage joint members and gaskets or encourage stress cracking.

If more preload is not a possibility, there are other options such as altering the stiffness ratios between the bolt and the joint, or using similar materials for bolt and joint members.

\section{Composite Joint Design}

Composite joints are significantly more complicated than their metallic counterparts because of the brittle nature of composite materials and the additional failure modes not present in metal structures. The following article discusses some common problems and presents design guidance to both the composite designer and stress analyst.

Highly loaded primary composite structures are feasible, but require more careful design than is customary for ductile metal joints. Additional failure modes due to the brittle nature of composites require additional attention from both the designer and analyst.

Although bolted composite joint design is straightforward, it requires additional analysis over metallic designs. The analysis calls for a major empirical correction factor in combination with additional composite material properties. The key to obtaining high operating strains in bolted composites joints is in restricting the bolt bearing stresses in the most critically loaded locations. The ability to do this depends on the availability of a good load-sharing analysis, such as finite element model (FEM), and sufficient test data to provide the input. However, accurate predictions have been made based on educated guesses where insufficient data were available. To predict accurate ultimate strength predictions, it is necessary to allow some bolts to fail in bearing and still take load while others begin to accept more load.

The most efficient joints have uniform un-reinforced skins to maximum the quality of the laminates and to permit straightforward bolted repairs in service in combination with reinforced tapered splice plates. Other joint geometries have been shown to be less efficient, both by analysis and test.

The step by step analysis procedure is involved and will not be covered in this article. The following Design Guidelines are recommended to maximize bolted joint performance in composites. 
It is imperative to use a bearing/bypass interaction equation to accurately analyze multi-row bolted composite joints. No matter the number of rows, maximum joint strength is achieved by keeping the bearing stresses low and maintaining recommended thickness to diameter rations and width to diameter ratios.

\section{Experimental Investigations}

In this chapter the Preparation of test specimen (composite coupons) and the procedure involved to study the bearing failure of double shear bolted joint are studied and the specimen is tested in laboratory.

\section{A. ASTM D5961 Method:}

This test method is particularly designed to determine the bearing response of composite laminates. The standard covers different procedures including the following:

1) Procedure ' $A$ ' double shear test

2) Procedure 'B' single shear test for two piece specimen.

3) Procedure ' $\mathrm{C}$ ' single shear test for single piece specimen.

\section{B. Procedure B, Double Shear, Tension:}

The flat, constant rectangular cross-section test specimen is composed of two like halves fastened together through one or two centerline holes located near one end of each half, as shown in the test specimen drawings of Fig.2. The eccentricity in applied force that would otherwise result is minimized by a doubler bonded to, or frictionally retained against each grip end of the specimen, resulting in a force line-of-action along the interface between the specimen halves, through the centerline of the hole(s).

Both the applied force and the associated deformation of the hole(s) are monitored. The deformation of the hole(s) is normalized by the hole diameter (a factor of two used to adjust for hole deformation occurring in the two halves) to result in an effective bearing strain. Likewise, the applied force is normalized by the projected whole area to yield an effective bearing stress. The specimen is loaded until a maximum force has clearly been reached, where upon the test is terminated so as to prevent masking of the true failure mode by large-scale hole distortion, in order to provide a more representative failure mode assessment. Bearing stress versus bearing strain for the entire loading regime is plotted, and failure mode noted. The ultimate bearing strength of the material is determined from the maximum force carried prior to test termination.

The standard test configuration for this procedure does not allow any variation of the major test parameters. However, the following variations in specimen and test fixture configuration are allowed, but can be considered as being in accordance with this test method only as long as the values of all variant test parameters are prominently documented with the results.

\section{Test Coupon Geometry:}

Bolt Diameter (d): $6+0.00 /-0.003 \mathrm{~mm}$

Coupon Hole Diameter (D): 6+0.00/-0.003 mm

Coupon Thickness Range (h): 3 to5 mm

Length of Coupon (L): $210 \mathrm{~mm}$

Width of coupon (w): $36+/-1 \mathrm{~mm}$

Distance from hole center to edge (e): $18+/-1 \mathrm{~mm}$

Doupler length (s): $50 \mathrm{~mm}$

The dimensions of the coupon Geometry are in conformance with ASTM D5961 test method for the Single Shear- Double Fastener -two piece Specimen.

\section{A. Number of Plies and Lay up arrangement:}

The arrangement and count of plies were finalized on the principle of percentage of different standard degrees in direction of plies as illustrated in fig.1. The layup arrangement for the fabric (E-glass) is Quasi isotropic. This layup was chosen in conferment of ASTM D5961 test standard for the procedure 'B'. Table.2 shows the details of layup arrangement and number of plies.

\section{B. Stacking Sequence:}

Stacking Sequence followed was Quasi-Isotropic Sequence. Symmetric balanced and unbalanced configurations for were used $4.2 \mathrm{~mm}$ and $3 \mathrm{~mm}$ coupons respectively.

[0/90/45/-45/0/90/45/-45/0/-45/45/90/0/-45/45/90/0] = symmetric unbalanced.

[0/90/45/-45/0/90/45/-45/0/90/45/-45/-45/45/90/0/-45/45/90/0/-45/45/90/0] = Symmetric balanced . 
Table 1: Laminate Configuration for Plain Weave Fabric Materials

\begin{tabular}{|l|l|l|l|l|}
\hline Material & Lay up $\%\left(\mathbf{0}^{\mathbf{\%}} \mathbf{4 5}^{\mathbf{\%}} \mathbf{\mathbf { 9 0 } ^ { \mathbf { 0 } } )}\right.$ & Ply Stacking Sequence & Total Plies & Nominal Thickness(mm) \\
\hline $\begin{array}{l}\text { E- GLASS } \\
\text { EPOXY }\end{array}$ & $25 / 50 / 25$ & {$[0 / 45 / 90 /-45] 2 \mathrm{~S}$} & 24 & 3.1 \\
\hline $\begin{array}{l}\text { E- GLASS } \\
\text { EPOXY }\end{array}$ & $25 / 50 / 25$ & {$[0 / 45 / 90 /-45] \mathrm{S}$} & 17 & 4.3 \\
\hline
\end{tabular}

\section{Coupon Fabrication:}

Selection of glass fabric: Fabric is woven by fibers. In market, there are different styles / varieties of fabrics are available. Before selection, properties of fiber are evaluated and if it is satisfactory then can go for fabric selection. E-glass fiber is applicable in design of rocket motor casing due to its Good thermal insulation, High ratio of surface area to weight, Elastic recovery, Heat and electrical resistance.

\section{Mold design and preparation:}

Mold design is shown in figure 3.2. Mold should be degreased before layup is started and should have smooth surface. To obtain these characteristics to the mold, emery paper $(80 \mu \mathrm{m})$ was used to degrease the mold; later acetone was used as mold cleaner and Aerosol mold release spray as releasing agent

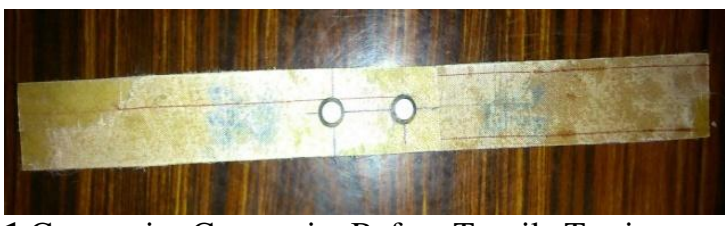

fig 3.1 Composite-Composite Before Tensile Testing

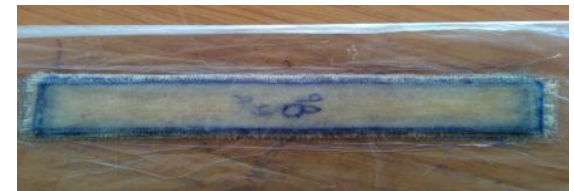

fig 3.2 Arrangement of mold before curing

Table2: Cutting temperatures

\begin{tabular}{|l|l|l|l|l|}
\hline Temperature range $\left({ }^{\circ} \boldsymbol{C}\right)$ & Room temp to 90 & At 90 & $90-120$ & At 120 \\
\hline Time & $10-15 \mathrm{~min}$ & $30 \mathrm{~min}$ & $10-15 \mathrm{~min}$ & $1 \mathrm{~h}$ \\
\hline Temperature range $\left({ }^{\circ} \boldsymbol{C}\right)$ & $120-150$ & At150 & $150-170$ & At 170 \\
\hline Time & $10-15 \mathrm{~min}$ & $1 \mathrm{~h}$ & $10-15 \mathrm{~min}$ & $1 \mathrm{~h}$ \\
\hline Temperature range $\left({ }^{\circ} \boldsymbol{C}\right)$ & $\begin{array}{l}\text { Room temperature } \\
\text { to } 90\end{array}$ & At 90 & $90-120$ & At 120 \\
\hline Time & $10-15 \mathrm{~min}$ & $30 \mathrm{~min}$ & $10-15 \mathrm{~min}$ & $1 \mathrm{~h}$ \\
\hline Temperature range $\left({ }^{\circ} \boldsymbol{C}\right)$ & $120-150$ & At150 & $150-170$ & At 170 \\
\hline Time & $10-15 \mathrm{~min}$ & $1 \mathrm{~h}$ & $10-15 \mathrm{~min}$ & $1 \mathrm{~h}$ \\
\hline
\end{tabular}

\section{Curing process:}

Curing process of stacked prepregs can be done at autoclave, hot air oven or through compression molding technique. Curing cycle can be done in two ways. One is step curing and the other is constant curing cycle. Mostly step curing cycle is preferred.

Table 2: Preferred curing cycle for Phenolic laminate

And then it is gradually cooled to room temperature in the oven itself.

\section{Mixing of $\mathrm{SiO}_{2}$ as filler:}

Phenolic laminates are manufactured with and without filler materials. Based on the type of filler material and \% of mixing of filler, the strength of material will be depends. [3] studied and wish to finding out few mechanical properties that, the composite specimens are manufactured from bi-directional woven ceramic fiber and ultra-light micro Silica filled Phenolic resin using traditional hand layup method. The percentage of weigh of ultra-light micro Silica varied from 5-20\% in the Phenolic resin. Initially, micro Silica is mixed with pre calculated Phenolic resin. Then this mixture was stirred slowly and thoroughly for about $30 \mathrm{~min}$ by using handheld electrical stirrer.

From the experimental result of tensile test, it is observed that the addition of micro Silica with Phenolic resin up to $15 \%$ increases the tensile strength of the composite. When compared to neat composite, addition of filler from 5-15\%, tensile strength, compression strength and Charpy impact strength are increased from $30-55 \%, 26-48 \%$ and $28-56 \%$ respectively.

Summary: Based on above study it is understood that E glass fiber has approximately $3 \%$ low density \& $20 \%$ higher $\mathrm{SiO}_{2}$ and its applicability in rocket motor casing. The experimentation and testing procedures at each stage of making laminate are also understood. The test results are discussed \& analyzed.

\begin{tabular}{l}
\hline International Conference on Recent Innovations in Civil \& Mechanical Engineering \\
[i-CAM2K16] DOI: 10.9790/1684-16053030106
\end{tabular}




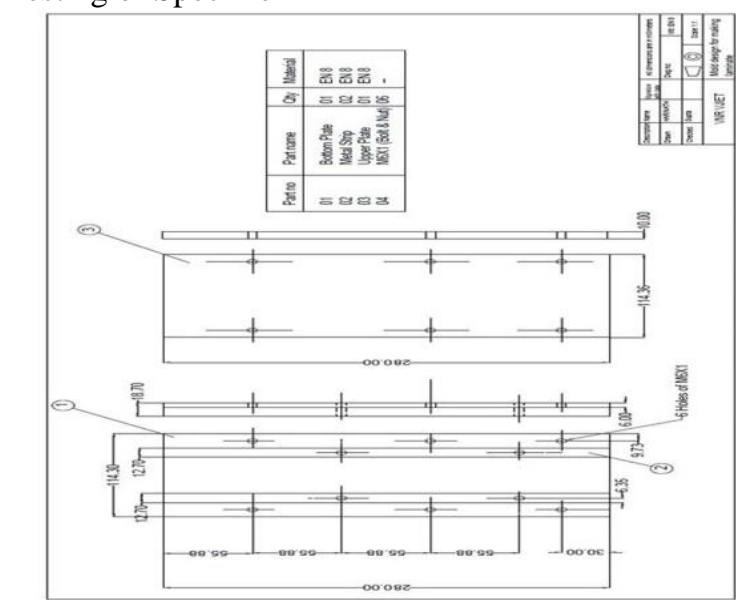

Fig.4.1: Mold Design for Making Composite Laminate

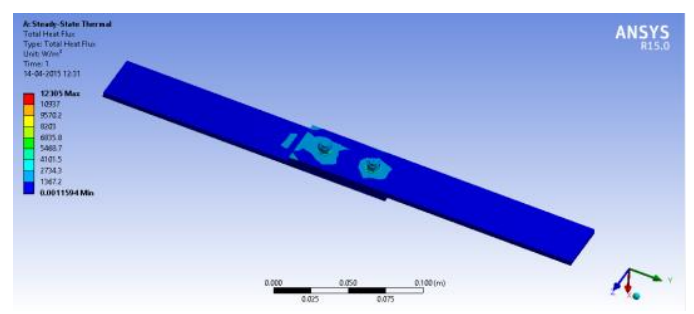

Fig 4.3: Total heat flux in Composite - Composite Couple Field Analysis

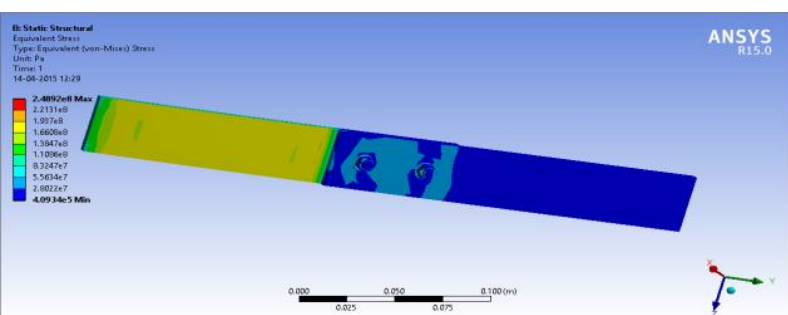

Fig4.2 Stress Distribution in Composite - Composite in Couple Field Analysis

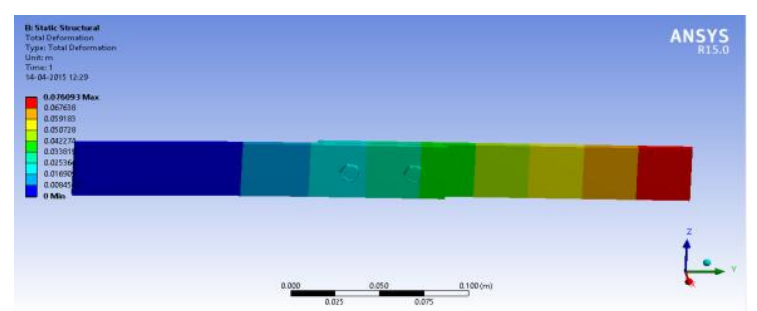

Fig4.4: Deformation of Composite - Composite in in Couple Field Analysis

\section{Setting up the test specimen}

The test is performed on a Universal Tensile Machine of capacity 10 tons. The bolts are tightened with a torque of 2.2-3.4 N-m (Hand tightened). The two test Specimen joints tested are Composite-Composite joint and Composite-Aluminum joint. The thickness of each laminate in Composite-Composite joint is $4.2 \mathrm{~mm}$ whereas of Composite-Aluminum joint is $3 \mathrm{~mm}$. The clamp length in $50 \mathrm{~mm}$. Doublers of $50 \mathrm{~mm}$ length is used on both ends of the bolted joint specimen so that there is no offset in the application of load. Doublers ensure that the line of action of applied force is parallel to length of specimen and perpendicular to the width.

The specimen is clamped and held tightly in the UTM. The bottom coupon is fixed in the lower jaw and a force pulls the upper coupon longitudinally. The load is controlled manually and the corresponding LoadDisplacement graph is plotted simultaneously in the computer connected to it.

\section{Specimen: Composite - Composite}

\section{Results of Testing}

In the Composite-Composite joint as both the coupons are of composite material. One of them is fixed in lower jaw and the force is applied in longitudinal direction by the upper jaw. Both the coupons are of $4.2 \mathrm{~mm}$ thickness so the doubles used are also of $4.2 \mathrm{~mm}$ thickness. The Ultimate breaking point has occurred at $9.9 \mathrm{KN}$

Common Modes of Failure in Bearing Test

The common modes of failure include the following: Laminate cleavage, Laminate Shear-out, Laminate tearout, Laminate Delamination and Lateral tension failure. The bearing test failure codes are illustrated in Table 3 .

\begin{tabular}{|c|c|c|}
\hline Property & Experimental Values & Computational Values \\
\hline & Composite- composite & Composite- composite \\
\hline Yield Strength $(\mathrm{KN})$ & 6.5 & 3.75 \\
\hline Ultimate Strength $(\mathrm{KN})$ & 9.72 & $9.9-$ \\
\hline Displacement (mm) & 12 & 13.2 \\
\hline Factor of Safety & - & 1.03 \\
\hline
\end{tabular}




\section{TABLE 3: Results}

In the composite - composite laminate the failure of the composite started at $3.75 \mathrm{KN}$ i.e., at the hole deformation starts and the laminate may fail transversely due to the load. There is a Deviation in the computational and experimental techniques because in computational technique ideal conditions are considered but coming to experimental technique there is chance of variation in load distribution, temperature conditions, surroundings May result some variation in results.

\section{Conclusion}

Damage analysis of double bolted single lap shear joint and various scenarios of bolt tightness are studied. ASTM standard method for bearing response of composite bolted joint are studied and analysed. Due to high cost of Carbon and unavailability of $\mathrm{S}$ glass fabric, $\mathrm{E}$ glass fabric is chosen to fabricate laminates, add $\mathrm{SiO}_{2}$ to the matrix to improve mechanical properties

\section{References}

[1]. Sayed A. Nassar, Vinayshankar L.Virupaksha, Saravanan Ganeshmurthy, "Effect of Bolt Tightness on the Behaviour of composite joints", Journal of Fastening and Joining Research Institute, Department of Mechanical Engineering, Oakland University, Vol. 129, FEBRUARY 2007, pp.

[2]. Yanyao Jiang, Ming Zhang, Chu-Hwa Lee, “A Study of Early Stage Self-Loosening of Bolted Joints” Journal of Mechanical Engineering, University of Nevada,SEPTEMBER 2003, Vol. 125,pp.

[3]. P.S. Parameswaran, "Modification of Phenol Formaldehyde Resin for Improved Mechanical Properties", PhD Thesis from Cochin University of Science andf Technology, 10606/8942, May 2013, pp. 02-46.

[4]. ASTM D 792 - Test Methods for Density and Specific Gravity (Relative Density) of Plastics by Displacement.

[5]. $\quad$ ASTM D883 - Terminology Relating to Plastics.

[6]. ASTM D2584 - Test Method for Ignition Loss of Cured Reinforced Resins.

[7]. $\quad$ ASTM D2734 - Test Methods for Void Content of Reinforced Plastics.

[8]. ASTM D3171 - Test Methods for Constituent Content of Composite Materials.

[9]. ASTM D3410/D3410M - Test Method for Compressive Properties of Polymer Matrix Composite Materials with Unsupported Gage Section by Shear Loading.

[10]. Prepreg, "From Art to Science: A Prepreg Overview", High Performance Composites, May/June 2000, pp. 32 - 36. 